\title{
The Human Reliability Research of VDT Operation Based on Task Characteristics and Operator Familiarity
}

\author{
Junhao Luo ${ }^{1, a}$, Bin Liao ${ }^{1, b}$, Kailun Yue ${ }^{1, \mathrm{c}}$ and Huimin Teng ${ }^{1, \mathrm{~d}}$ \\ ${ }^{1}$ School of Business, Sichuan Normal University, Chengdu 610101, China

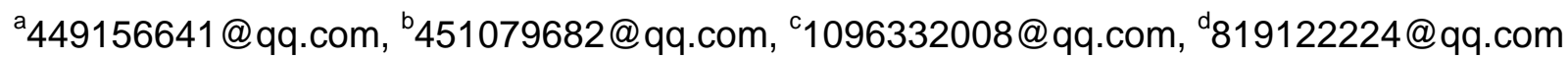

\begin{abstract}
Keywords: Visual display terminal (VDT), Human-Computer interaction (HCI), Operator familiarity, Task characteristics, Human reliability.

Abstract. In order to explore the effects of task characteristics and operator familiarity on human reliability in human-computer interaction VDT operation, the simulation experiment was designed, then the performance data of 20 healthy college students were collected and analyzed by analysis of variance (ANOVA). The results indicate that the main effects of task characteristics and operator familiarity on correct rate and response time are significant, but their interaction effects are significant only on response time. With the improvement of operator familiarity, the response of participants become faster, and this trend is more obvious in the task of high complexity, so the training mechanism of VDT operators should be pay attention to cautiously, especially for the task of high cognitive loads. This study demonstrates that strengthening the operator familiarity of VDT operators in high complexity task can effectively improve system performance and security.
\end{abstract}

\section{Introduction}

The visual display terminal (VDT) operation is referred to as a general term of using computer systems to process characters, images and other information, it has become the most typical form of labor in today's society, especially for the VDT operation of human-computer interaction (HCI). The performance level of human being that usually takes human reliability as evaluation index is an important component of the system security and reliability in this complex mental work. Human reliability is the probability that a person can complete the task successfully within the stipulated time, in any period of the system [1]. A lot of data shows that nearly $60 \%$ of the world's annual system failure accidents are related to human reliability, and significant accidents could be as high as $80 \%$ [2]. Therefore, the human reliability analysis in VDT operation should not be ignored.

The influence factors of human reliability include work environment, task characteristics and individual factors [3], and the influence of task characteristics is the most significant [4]. Jinbo Li had explored the synthetic effect of task and individual characteristics on cognitive load [5], but the memory effect, that is operator familiarity, is not considered, which is ubiquitous in the individual factors. Operator familiarity generally refers to the experience of operators to cognize information that is related to some specific object [6]. It restricts the attention resources required by the task and then affects the performance of the task [7]. In addition, it is not sure that there are interaction effects between task characteristics and operator familiarity.

Based on the analysis above, the author will take task characteristics and operator familiarity as independent variables, design the simulation experiment of human-computer interaction VDT operation. And the performance data of the human reliability will be collected for statistical analysis. This study can provide a basis for improving the performance and safety of VDT operation system.

\section{Method}

Design. The experiment used 6 (task complexity) $* 3$ (operator phase) within-subjects and two-factor repeated measurement design, it had 18 experimental levels in total, as shown in Tab. 1. The task complexity was used to distinguish various task characteristics, represented by $A_{i}$, including 6 levels ( $\mathrm{i}=1 \sim 6): \mathrm{A}_{1}$ (simple matching task), $\mathrm{A}_{2}$ (type identification task), $\mathrm{A}_{3}$ (blank filling task), $\mathrm{A}_{4}$ (words 
inference task), $\mathrm{A}_{5}$ (numbers inference task) and $\mathrm{A}_{6}$ (pictures inference task). The operator familiarity was controlled through the operator phase, represented by $B_{j}$, including 3 levels $(j=1 \sim 3)$ : $B_{1}$ (phase one), $\mathrm{B}_{2}$ (phase two) and $\mathrm{B}_{3}$ (phase three). Each task must be completed in 3 phases (including 20 identical trials) in turn, the memory effects of participants were produced through the reproduction of the material, so the operator familiarity would increase 3 times.

Tab. 1 Experimental Level Design

\begin{tabular}{ccccccc}
\hline & Simple & Type & Blank & Words & Numbers & Pictures \\
& Matching & Identification & Filling & Inference & Inference \\
Task & Task & Task & Task & Task & Task \\
\hline Phase One & $\mathrm{A}_{1} \mathrm{~B}_{1}$ & $\mathrm{~A}_{2} \mathrm{~B}_{1}$ & $\mathrm{~A}_{3} \mathrm{~B}_{1}$ & $\mathrm{~A}_{4} \mathrm{~B}_{1}$ & $\mathrm{~A}_{5} \mathrm{~B}_{1}$ & $\mathrm{~A}_{6} \mathrm{~B}_{1}$ \\
Phase Tow & $\mathrm{A}_{1} \mathrm{~B}_{2}$ & $\mathrm{~A}_{2} \mathrm{~B}_{2}$ & $\mathrm{~A}_{3} \mathrm{~B}_{2}$ & $\mathrm{~A}_{4} \mathrm{~B}_{2}$ & $\mathrm{~A}_{5} \mathrm{~B}_{2}$ & $\mathrm{~A}_{6} \mathrm{~B}_{2}$ \\
Phase Three & $\mathrm{A}_{1} \mathrm{~B}_{3}$ & $\mathrm{~A}_{2} \mathrm{~B}_{3}$ & $\mathrm{~A}_{3} \mathrm{~B}_{3}$ & $\mathrm{~A}_{4} \mathrm{~B}_{3}$ & $\mathrm{~A}_{5} \mathrm{~B}_{3}$ & $\mathrm{~A}_{6} \mathrm{~B}_{3}$ \\
\hline
\end{tabular}

The Experiment was realized by E-Prime 2.0, and used parallel mode, consisted of 3 List (to store materials and related controller) and 3 Core Experimental Procedure (CEP). The response instrument was keyboard. Each task was equipped with the experimental instruction which inform the experimental content and mode of operation. Each Trial started when the prompt "+" appeared from the center of screen, then presented the stimulus \& probe interface. This interface consisted of 1 description and 4 options: "A", "B", "C" and "D", participants must made a choice after reading and thinking, thus completed the human-computer interaction. Then the feedback interface appeared immediately, showing the response time of the last trial and the cumulative correct rate. Feedback formed the Inter-Stimulus Interval (ISI), then next trial started, until the CEP over. In the end, presentation interface appeared, as a token of gratitude. The operating indication is shown in Fig. 1.

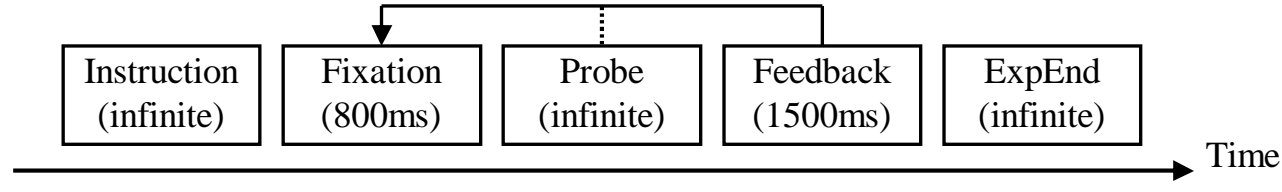

Fig. 1 Operating Indication of Complete Trial

Equipment and Environment. The Experiment used Lenovo notebook Y500N-IFI (A), equipped with 15.6 inch LCD (resolution: 1366 * 768). The screen was clear, and it's brightness was moderate. This computer was installed Windows 8 system (64 bit), and it ran smoothly. Experimental site was the university laboratory where was bright and quiet.

Participants. A total of 20 college students participated in the experiment, including 10 boys and 10 girls, whose age ranged from 19 to 24 . All of the participants had normal uncorrected visual acuity, and their physical and mental were both healthy. All of them were right-handed.

Process. The experiment was conducted separately on each of participants, they must complete all the tasks in 3 phases of various task complexity in order. A full demonstration was carried out before the start of the experiment. After the participant had mastered the operation method, the experiment began. Each task lasted about 10 minutes, and the rest time was 2 minutes.

Data Collection and Arrangement. The experiment collected correct rate and response time as the specific data of human reliability to analyze. E-Prime 2.0 automatically collected accuracy (ACC) and response time (RT) of each trial during the experiment. Excel was used to calculate the cumulative correct rate and average response time of each participant.

\section{Analysis}

According to 18 different levels of experimental variables, the data were classified into groups. Then ANOVA was performed using SPSS 20, which took correct rate and response time as the dependent variables, task complexity and operator phase as the fixed factors. 
Tab. 2 Mauchly's Test of Sphericity

\begin{tabular}{ccccccccc}
\hline $\begin{array}{c}\text { Dependent } \\
\text { Variable }\end{array}$ & $\begin{array}{c}\text { Within Subjects } \\
\text { Effect }\end{array}$ & $\begin{array}{c}\text { Mauchly's } \\
\text { W }\end{array}$ & $\begin{array}{c}\text { Approx. } \\
\text { Chi-Square }\end{array}$ & df & Sig. & \multicolumn{4}{c}{ Ereenhouse } & $\begin{array}{c}\text { Huynh } \\
\text {-Felon }\end{array}$ & $\begin{array}{c}\text { Lower } \\
\text {-bound }\end{array}$ \\
\hline Correct & $\mathrm{A}$ & 0.341 & 18.385 & 14 & 0.194 & 0.722 & 0.912 & 0.200 \\
Rate & $\mathrm{B}$ & 0.909 & 1.708 & 2 & 0.426 & 0.917 & 1.000 & 0.500 \\
& $\mathrm{~A} * \mathrm{~B}$ & 0.010 & 71.719 & 54 & 0.071 & 0.533 & 0.766 & 0.100 \\
Response & $\mathrm{A}$ & 0.012 & 76.130 & 14 & 0.000 & 0.471 & 0.541 & 0.200 \\
Time & $\mathrm{B}$ & 0.386 & 17.158 & 2 & 0.000 & 0.619 & 0.641 & 0.500 \\
& $\mathrm{~A} * \mathrm{~B}$ & 0.000 & 169.852 & 54 & 0.000 & 0.281 & 0.334 & 0.100 \\
\hline
\end{tabular}

*. Interaction effects between variables

Since A and B both have 3 or more variables, it is necessary to carry out the Mauchly's Test of Sphericity, and the results are shown in Tab. 2. Under the correct rate index, A: $\mathrm{P}=0.194>0.05, \mathrm{~B}$ : $\mathrm{P}=0.426>0.05, \mathrm{~A}^{*} \mathrm{~B}: \mathrm{P}=0.071>0.05$, they are all meet the test, so the one-way ANOVA should refer to the results of Sphericity Assumed. Under the response time index, A, B and A*B are not meet the test $(\mathrm{P}=0.000<0.05)$, so correct them using Greenhouse-Geisser method.

Tab. 3 Tests of Within-Subjects Effects

\begin{tabular}{|c|c|c|c|c|c|c|c|}
\hline $\begin{array}{c}\text { Dependent } \\
\text { Variable } \\
\end{array}$ & & Source & df & $\mathrm{F}$ & Sig. & $\begin{array}{c}\text { Partial Eta } \\
\text { Squared } \\
\end{array}$ & $\begin{array}{c}\text { Observed } \\
\text { Power }^{\mathrm{a}}\end{array}$ \\
\hline \multirow{3}{*}{$\begin{array}{l}\text { Correct } \\
\text { Rate }\end{array}$} & $\overline{\mathrm{A}}$ & Sphericity Assumed & 5 & 37.830 & 0.000 & 0.666 & 1.000 \\
\hline & B & Sphericity Assumed & 2 & 22.851 & 0.000 & 0.546 & 1.000 \\
\hline & $A * B$ & Sphericity Assumed & 10 & 0.762 & 0.666 & 0.039 & 0.394 \\
\hline \multirow{3}{*}{$\begin{array}{l}\text { Response } \\
\text { Time }\end{array}$} & A & Greenhouse-Geisser & 2.354 & 45.569 & 0.000 & 0.706 & 1.000 \\
\hline & B & Greenhouse-Geisser & 1.239 & 114.243 & 0.000 & 0.857 & 1.000 \\
\hline & $A * B$ & Greenhouse-Geisser & 2.806 & 38.956 & 0.000 & 0.672 & 1.000 \\
\hline
\end{tabular}

*. Interaction effects between variables

a. Computed using alpha $=0.05$

The results of Tests of Within-Subjects Effects are shown in Tab. 3. Under the correct rate index, the main effects of $\mathrm{A}$ and $\mathrm{B}$ are both very significant $(\mathrm{P}=0.000<0.01)$, but the interaction effects between $\mathrm{A}$ and $\mathrm{B}$ are not significant $(\mathrm{P}=0.666>0.05)$. Under the response time index, the main effects of $\mathrm{A}$ and $\mathrm{B}$ are both very significant $(\mathrm{P}=0.000<0.01)$, the interaction effects between $\mathrm{A}$ and $\mathrm{B}$ are also very significant $(\mathrm{P}=0.000<0.01)$, and the Partial Eta Squared is 0.672 , the Observed Power is 1 . It can be concluded that the operator familiarity and task complexity of VDT operation have significant influence on the human reliability, but their interaction influence is only significant on response time. 
Tab. 4 Pairwise Comparisons

\begin{tabular}{|c|c|c|c|c|c|c|c|c|c|c|c|c|c|c|}
\hline A & $\begin{array}{c}\text { (I) } \\
\text { B }\end{array}$ & $\begin{array}{c}(\mathrm{J}) \\
\mathrm{B}\end{array}$ & $\begin{array}{c}\text { Mean } \\
\text { Difference } \\
\text { (I-J) }\end{array}$ & Sig. ${ }^{a}$ & A & $\begin{array}{c}\text { (I) } \\
\text { B }\end{array}$ & $\begin{array}{c}(\mathrm{J}) \\
\text { B }\end{array}$ & $\begin{array}{c}\text { Mean } \\
\text { Difference } \\
(\mathrm{I}-\mathrm{J})\end{array}$ & Sig. ${ }^{a}$ & A & $\begin{array}{l}\text { (I) } \\
\mathrm{B}\end{array}$ & $\begin{array}{c}(\mathrm{J}) \\
\text { B }\end{array}$ & $\begin{array}{c}\text { Mean } \\
\text { Difference } \\
\text { (I-J) }\end{array}$ & Sig. ${ }^{a}$ \\
\hline \multirow{6}{*}{1} & \multirow{2}{*}{1} & 2 & $3.979 *$ & 0.000 & & \multirow{2}{*}{1} & 2 & $1.933^{*}$ & 0.000 & & & 2 & $13.200^{*}$ & 0.000 \\
\hline & & 3 & $4.192 *$ & 0.000 & & & 3 & $2.651 *$ & 0.000 & & & 3 & 15.58 & 0.000 \\
\hline & \multirow{2}{*}{2} & 1 & $-3.979 *$ & 0.000 & \multirow{2}{*}{3} & \multirow{2}{*}{2} & 1 & $-1.933^{*}$ & 0.000 & \multirow{2}{*}{5} & \multirow{2}{*}{2} & 1 & $-13.200^{*}$ & 0.000 \\
\hline & & 3 & 0.213 & 0.914 & & & 3 & $0.718^{*}$ & 0.019 & & & 3 & $2.383 *$ & 0.000 \\
\hline & \multirow{2}{*}{3} & 1 & $-4.192 *$ & 0.000 & & \multirow{2}{*}{3} & \multirow{2}{*}{$\begin{array}{l}1 \\
2\end{array}$} & $-2.651 *$ & 0.000 & & \multirow{2}{*}{3} & \multirow{2}{*}{$\begin{array}{l}1 \\
2\end{array}$} & $-15.584 *$ & 0.000 \\
\hline & & 2 & -0.213 & 0.914 & & & & $-0.718^{*}$ & 0.019 & & & & $-2.383^{*}$ & 0.000 \\
\hline \multirow{6}{*}{2} & & 2 & $3.444 *$ & 0.000 & & \multirow{2}{*}{1} & 2 & $4.518^{*}$ & 0.000 & & \multirow{2}{*}{1} & 2 & $13.634 *$ & 0.000 \\
\hline & 1 & 3 & $5.055^{*}$ & 0.000 & & & 3 & $5.937 *$ & 0.000 & & & 3 & $16.249 *$ & 0.000 \\
\hline & & 1 & $-3.444 *$ & 0.000 & \multirow{4}{*}{4} & \multirow{2}{*}{2} & 1 & $-4.518^{*}$ & 0.000 & \multirow{2}{*}{6} & \multirow[b]{2}{*}{2} & 1 & $-13.634 *$ & 0.000 \\
\hline & 2 & 3 & $1.611^{*}$ & 0.000 & & & 3 & $1.419 *$ & 0.017 & & & 3 & $2.614^{*}$ & 0.011 \\
\hline & \multirow{2}{*}{3} & 1 & $-5.055^{*}$ & 0.000 & & \multirow{2}{*}{3} & 1 & $-5.937 *$ & 0.000 & & \multirow[b]{2}{*}{3} & 1 & $-16.249 *$ & 0.000 \\
\hline & & 2 & $-1.611 *$ & 0.000 & & & 2 & $-1.419 *$ & 0.017 & & & 2 & $-2.614^{*}$ & 0.011 \\
\hline
\end{tabular}

*. The mean difference is significant at the 0.05 level.

a. Adjustment for multiple comparisons: Sidak.

A simple effect test is used to test the response time, and the results are shown in Tab. 4. The response time have extremely significant differences between most of the phases $(\mathrm{P}=0.000<0.01)$, except for the second and the third operator phase of the simple matching task. The sequence of response time is the first phase, the second phase and the third phase (difference between the first two phases are bigger), and such rule becomes more obvious from the fourth task complexity.

\section{Discussion}

In this study, the simulation experiment of human-computer interaction VDT operation was design, which took correct rate and respond time of participants as indexes, for exploring the effects of task characteristics and operator familiarity on human reliability. The results show that operator familiarity and task complexity have significant effects on response time and correct rate, but their interaction effects are significant only on response time. According to the simple effect test results, for any task complexity, the operators process tasks faster and faster with the operator familiarity improves gradually, and it is more obvious in the task of high complexity that has more attention resources and needs more information processing, such as logic reasoning tasks. Therefore, strengthening the operator familiarity in human-computer interaction VDT operation is one of the most important measures to improve system performance and security that can not be ignore.

\section{Conclusions}

(1) In human-computer interaction VDT operation, task complexity and operator familiarity have significant effects on human reliability, and their interaction effects are also significant.

(2) The greater cognitive load in VDT operation, the more attention should be paid to the training mechanism of operators, so that the system performance and security can be improved effectively.

(3) Operator familiarity of VDT operation increases mainly in the early phase, so the operator training should focus on the preliminary stage of learning.

\section{Acknowledgements}

This work was financially supported by the MOE (Ministry of Education in China) Youth Project of Humanities and Social Sciences (14YJCZH089), the Social Science Foundation of Sichuan Province 
of China (SC16B065) and Sichuan Province Undergraduate Training Program for Innovation and Entrepreneurship (201610636145).

\section{References}

[1] Pengcheng Li, Guohua Chen, Li Zhang and et al: Atomic Energy Science and Technology, in Chinese, Vol. 45-3 (2011), p. 329-340.

[2] Fuqiang Yang, Chao Wu, Fasong Wang and et al: Science \& Technology Review, in Chinese, Vol. 27-8 (2009), p. 87-94.

[3] Baihua $\mathrm{Xu}$, Yaqiang $\mathrm{Fu}$ and He Liang: Chinese Journal of Ergonomics, in Chinese, Vol. 6-4 (2000), p. 12-14.

[4] Huimin Teng, Bin Liao and Junhao Luo: Chinese Journal of Ergonomics, in Chinese, Vol. 22-5 (2016), p. 45-49.

[5] Jinbo Li: Psychological Science, in Chinese, Vol. 33-4 (2010), p. 972-975.

[6] Hongsheng Yang: Psychological Science, in Chinese, Vol. 36-5 (2013), p. 1058-1065.

[7] Yudi Zhang, Huiying Shi: Psychological Science, in Chinese, Vol. 33-4 (2010), p. 896-899. 